\title{
Advection of $\mathrm{NH}_{3}$ over a pasture field and its effect on gradient flux measurements
}

\author{
B. Loubet ${ }^{1}$, C. Milford ${ }^{2,}{ }^{*}$, A. Hensen ${ }^{3}$, U. Daemmgen ${ }^{4}$, J.-W. Erisman ${ }^{3}$, P. Cellier ${ }^{1}$, and M. A. Sutton ${ }^{2}$ \\ ${ }^{1}$ Institut National de la Recherche Agronomique (INRA), UMR Environnement et Grandes Cultures, \\ 78850 Thiverval-Grignon, France \\ ${ }^{2}$ Centre for Ecology and Hydrology (Edinburgh Research Station), Bush Estate, Penicuik, Midlothian, EH26 0QB, UK \\ ${ }^{3}$ Energy research Centre of the Netherlands (ECN), Postbus 1, 1755 ZG Petten, The Netherlands \\ ${ }^{4}$ Inst. für Agrarökologie, Bundesforschungsanstalt für Landwirtschaft (FAL), Bundesallee 50, 38116 Braunschweig, Germany \\ "now at: Institute of Earth Sciences "Jaume Almera", CSIC, Lluis Solé i Sabarís, 08028 Barcelona, Spain
}

Received: 7 October 2008 - Published in Biogeosciences Discuss.: 6 January 2009

Revised: 22 June 2009 - Accepted: 22 June 2009 - Published: 28 July 2009

\begin{abstract}
Deposition of atmospheric ammonia $\left(\mathrm{NH}_{3}\right)$ to semi-natural ecosystems leads to serious adverse effects, such as acidification and eutrophication. A step in quantifying such effects is the measurement of $\mathrm{NH}_{3}$ fluxes over seminatural and agricultural land. However, measurement of $\mathrm{NH}_{3}$ fluxes over vegetation in the vicinity of strong $\mathrm{NH}_{3}$ sources is challenging, since $\mathrm{NH}_{3}$ emissions are highly heterogeneous. Indeed, under such conditions, local advection errors may alter the measured fluxes. In this study, local advection errors $\left(\Delta F_{\mathrm{Z}, \text { adv }}\right)$ were estimated over a 14 ha grassland field, which was successively cut and fertilised, as part of the GRAMINAE integrated Braunschweig experiment. The magnitude of $\Delta F_{\mathrm{Z}, \text { adv }}$ was determined up to $810 \mathrm{~m}$ downwind from farm buildings emitting between 6.2 and $9.9 \mathrm{~kg} \mathrm{NH}_{3}$ day $^{-1}$. The GRAMINAE experiment provided a unique opportunity to compare two methods of estimating $\Delta F_{\mathrm{z}, \text { adv }}$ : one inference method based on measurements of horizontal concentration gradients, and one based on inverse dispersion modelling with a two-dimensional model.
\end{abstract}

Two sources of local advection were clearly identified: the farm $\mathrm{NH}_{3}$ emissions leading to positive $\Delta F_{\mathrm{Z}, \text { adv }}$ ("bias towards emissions") and field $\mathrm{NH}_{3}$ emissions, which led to a negative $\Delta F_{\mathrm{z} \text {,adv }}$ ("bias towards deposition"). The local advection flux from the farm was in the range 0 to $27 \mathrm{ng} \mathrm{NH}_{3} \mathrm{~m}^{-2} \mathrm{~s}^{-1}$ at $610 \mathrm{~m}$ from the farm, whereas $\Delta F_{\mathrm{z} \text {,adv }}$ due to field emission was proportional to the local flux, and ranged between -209 and $13 \mathrm{ng} \mathrm{NH}_{3} \mathrm{~m}^{-2} \mathrm{~s}^{-1}$. The local advection flux $\Delta F_{\mathrm{z} \text {,adv }}$ was either positive or negative depend-

Correspondence to: $\mathrm{B}$. Loubet

(loubet@grignon.inra.fr) ing on the magnitude of these two contributions. The modelled and inferred advection errors agreed well. The inferred advection errors, relative to the vertical flux at $1 \mathrm{~m}$ height, were $52 \%$ on average, before the field was cut, and less than $2.1 \%$ when the field was fertilised. The variability of the advection errors in response to changes in micrometeorological conditions is also studied. The limits of the 2-D modelling approach are discussed.

\section{Introduction}

Ammonia has long been used by humans for manufacture and fertilization (Sutton et al., 2008). Deposition of atmospheric ammonia $\left(\mathrm{NH}_{3}\right)$ may lead to severe adverse effects on sensitive ecosystems, such as acidification and eutrophication (Fangmeier et al., 1994; Krupa, 2003), as well as to agricultural land that is typically exposed to larger $\mathrm{NH}_{3}$ concentrations (van der Eerden et al., 1998). Ammonia emissions mainly originate from farm livestock and field spread manure, as well as fields following the application of mineral fertilisers (Bouwman et al., 1997; Sommer et al., 2003). Estimating the net $\mathrm{NH}_{3}$ emissions from farms and their surrounding fields, which might act as sources or sinks depending on season and management (e.g., Milford et al., 2001b), is essential to quantify the net input of $\mathrm{NH}_{3}$ from agriculture to the atmosphere on a regional scale. Hence, measuring the $\mathrm{NH}_{3}$ flux with vegetation is necessary to (i) assess pollution impacts to sensitive ecosystems, as well as (ii) quantify $\mathrm{NH}_{3}$ emissions and deposition to agricultural fields. There are several ways of measuring $\mathrm{NH}_{3}$ fluxes between the atmosphere and the surface: the micrometeorological gradient

Published by Copernicus Publications on behalf of the European Geosciences Union. 


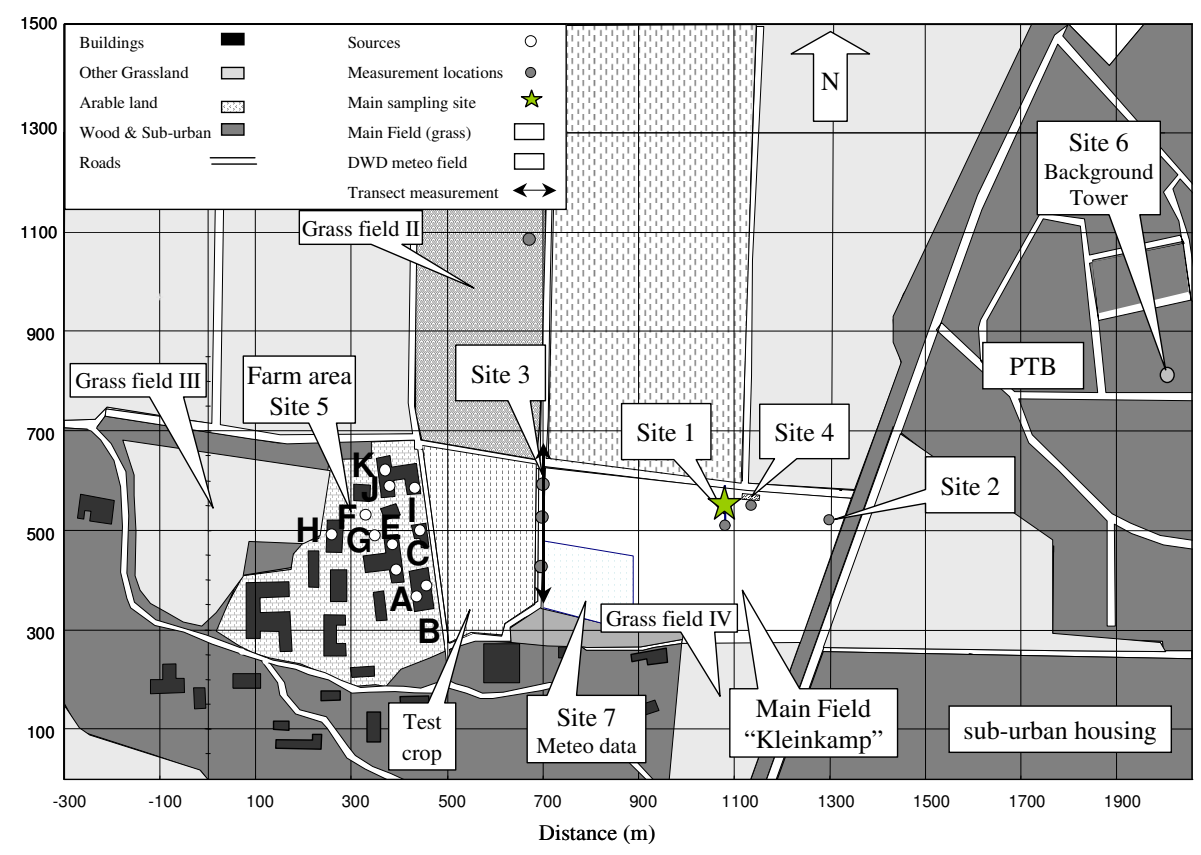

Fig. 1. Overview of the measurement site. The four concentration measurement locations used in this study are Site 1 , Site 2 , Site 3 , as well as Site 6 where the background concentration was measured. The $\mathrm{NH}_{3}$ source buildings are detailed in Sutton et al. (2009). Main Field is field I, and grass field II is the field where slurry was spread the 24 May 2000.

method (Erisman and Wyers, 1993; Fowler et al., 2001; Kruit et al., 2007; Sutton et al., 1993, 2001), the Bowen ratio method (Walker et al., 2006b), the Relaxed Eddy Accumulation method (REA) (Hensen et al., 2008; Kaimal and Finnigan, 1994), as well as the eddy-covariance method using for example tunable diode lasers (Famulari et al., 2004; Whitehead et al., 2008). All these methods rely on the assumption of non-divergence of the vertical flux (e.g., Foken et al., 2006; Fowler and Duyzer, 1989; Lee et al., 2004). Such divergence might exist in conditions of either (1) unsteadiness (temporal variation) of the flow or the sources/sinks, (2) chemical reactions consuming or releasing $\mathrm{NH}_{3}$ in the atmosphere, or (3) heterogeneity in the spatial distribution of the sources and sinks, either of momentum or $\mathrm{NH}_{3}$. Agricultural landscapes exhibit many of the undesired criteria: large $\mathrm{NH}_{3}$ sources, such as animal housing, grazing cattle or fields after manure or fertiliser application, are often in close juxtaposition to natural or agricultural ecosystems acting as $\mathrm{NH}_{3}$ receptors (Hertel et al., 2006; Sutton et al., 1998; Walker et al., 2006a). The short lifetime of $\mathrm{NH}_{3}$ in the atmosphere leads to rapid chemical reactions (Brost et al., 1988; Nemitz and Sutton, 2004; Nemitz et al., 1996, 2000, 2004). As a consequence, measurements of $\mathrm{NH}_{3}$ ground fluxes with micrometeorological methods may often be liable to errors due to divergence of the vertical flux, linked with the heterogeneity of the source and sinks, as well as chemical reactions (Nemitz and Sutton, 2004), leading to local advection (Loubet et al., 2001, 2006; Milford et al., 2001a).
In the present study, the local advection fluxes were estimated as part of the GRAMINAE Integrated Experiment (Sutton et al., 2009) over an experimental field of approximately $600 \mathrm{~m} \times 300 \mathrm{~m}$, located $230 \mathrm{~m}$ downwind of a set of farm buildings (Fig. 1) over a period of one month, during which the field was cut and fertilized. There were two sources of local advection fluxes: the farm buildings and the field itself (Fig. 1). This paper addresses the issue of advection using both inference from measurements and modelling. The latter is based on the inversion of a simplified two-dimensional dispersion-exchange model (Loubet et al., 2001 ) to fit measured concentration profiles at a known distance from a delimited source, and this technique also provides an alternative means to quantify net surface exchange fluxes in a similar manner as McInnes et al. (1985) and Wilson (1982).

\section{Theoretical background}

The conservation equation for $\mathrm{NH}_{3}$ in the atmospheric surface layer is (Fowler and Duyzer, 1989):

$$
\frac{\partial F_{\mathrm{z}}}{\partial z}=-\frac{\partial \chi_{\mathrm{a}}}{\partial t}-\frac{\partial F_{\mathrm{X}}}{\partial x}-\frac{\partial F_{\mathrm{y}}}{\partial y}+Q_{\text {chem }}
$$

where $z$ is the height above the displacement height $d, t$ is time, $x$ is downwind distance, $\chi_{a}$ is the $\mathrm{NH}_{3}$ concentration, $F_{\mathrm{x}}, F_{\mathrm{y}}$ and $F_{\mathrm{z}}$ are the horizontal, lateral and vertical components of the $\mathrm{NH}_{3}$ flux, respectively, and $Q_{\text {chem }}$ is the net 
chemical source density. The left-hand term, $\partial F_{\mathrm{Z}} / \partial z$, is the vertical flux divergence, (I) is the storage term, (II) and (III) are the horizontal and vertical flux divergences, respectively, and (IV) is the chemical source/sink term.

For $\mathrm{NH}_{3}$, which is rapidly exchanged with the surface, the storage term due to $\partial \chi_{\mathrm{a}} / \partial t$ is usually negligible (e.g. Sutton et al., 1993). In situations with sufficient concentrations, the perturbation of the $\mathrm{NH}_{3}-\mathrm{HNO}_{3}-\mathrm{NH}_{4} \mathrm{NO}_{3}$ and $\mathrm{NH}_{3}-\mathrm{HCl}-$ $\mathrm{NH}_{4} \mathrm{Cl}$ equilibriums due to fluxes at the surface can lead to a chemical production/consumption term $Q_{\text {chem }}$ (Nemitz et al., 2009a). This effect may potentially lead to errors of the order of $30 \%$ of $F_{\mathrm{Z}}$ (Nemitz et al., 1996). There is little information on the lateral flux divergence $\partial F_{y} / \partial y$ in the literature. Using the 3-D dispersion model of Huang (1979), described in Hensen et al. (2009), we found that $\partial F_{\mathrm{y}} / \partial y$ was smaller than $5 \%$ of the horizontal flux divergence $\partial F_{\mathrm{X}} / \partial x$ during $28 \%$ of the time, and smaller than $20 \%$ of $\partial F_{\mathrm{X}} / \partial x$ during $65 \%$ of the time for the situation encountered here. Although $\partial F_{\mathrm{y}} / \partial y$ can represent a fraction of $\partial F_{\mathrm{x}} / \partial x$, since during most of the time it was smaller than $20 \%$ of $\partial F x / \partial x$, $\partial F y / \partial y$ was neglected in this approach. Assuming furthermore that horizontal diffusion can be neglected compared to horizontal advection, which is a reasonable assumption above short vegetation (e.g., Leuning et al., 1985), $F_{\mathrm{x}}$ can be expressed as: $F_{\mathrm{X}}(x, z)=u(z) \chi_{\mathrm{a}}(x, z)$, where $u$ is the mean wind speed. The term (II) in Eq. (1) can then be integrated to get an expression of the vertical flux difference due to local advection $\Delta F_{z, \text { adv }}(x, z)$, at location $x$ and height $z$ (named local advection flux in the following):

$\Delta F_{\mathrm{z}, \mathrm{adv}}(x, z)=F_{\mathrm{Z}}(x, z)-F_{\mathrm{Z}}\left(x, z_{0}\right)=-\int_{z_{0}}^{z} u(z) \frac{\partial \chi_{\mathrm{a}}(x, z)}{\partial x} \partial z$

where $F_{\mathrm{Z}}$ is the vertical flux, $z_{0}$ is the roughness length, and $F_{\mathrm{Z}}\left(x, z_{0}\right)$ is the flux at the surface, which is what is sought in measurements. According to Eq. (2), a negative horizontal gradient of concentration (concentration decreasing with $x$ ) leads to a positive local advection flux, which corresponds to a situation downwind from a source and above a sink. On the contrary, a positive horizontal gradient of concentration leads to negative local advection fluxes, which corresponds to what would be observed above a source. Equation (2) also shows that if $\Delta F_{\mathrm{z}, \text { adv }}$ is positive, $F_{\mathrm{z}}$ is larger than the flux at the surface, hence measurements at a given height are "biased toward emission". On the contrary, a negative $\Delta F_{\mathrm{z} \text {, adv }}$ means a "bias toward deposition". The following sections detail how the vertical flux divergence is inferred from the horizontal concentration gradient and by inverse modelling.

\section{Materials and methods}

\subsection{Site description}

The field site was a 12 ha experimental grassland located in the grounds of the Forschungsanstalt Landwirtschaft (FAL), Braunschweig, Germany (Fig. 1). Directly adjacent to the field were an experimental farm of the FAL and a station of the German Weather Service (Deutscher Wetterdienst). The field site is described in detail in Sutton et al. (2009). The experiment lasted from 22 May 2000 to 15 June 2000, over a period when field I was cut (29 May 2000), and then fertilised with $100 \mathrm{~kg} \mathrm{NH}_{3} \mathrm{ha}^{-1}$ of calcium ammonium nitrate (5 June 2000).

The main sources of $\mathrm{NH}_{3}$ in the area were the set of farm buildings (Site 5 in Fig. 1), which were an emission source throughout the experimental period; the main field, which was a strong source after fertilisation, and a grass field (Grass field II in Fig. 1), which was spread with liquid manure on 24 May 2000. Other fields which may have been small $\mathrm{NH}_{3}$ sources (Fields III and IV) were not taken into account in this study. The distance from west to east is referred to as $x$, whereas the distance from south to north is referred to as $y$, while height above ground is $z$. The distance between the downwind edge of the farm building area and the different sites were estimated as $230 \mathrm{~m}$ for Site 3, $610 \mathrm{~m}$ for Site 1 and $810 \mathrm{~m}$ for Site 2. Site 6 was used for measuring the background concentration. The farm buildings themselves occupied an area of approximately $180 \mathrm{~m}(\mathrm{E}-\mathrm{W}) \times 200-300 \mathrm{~m}$ (S$\mathrm{N})$. The size of the equivalent two-dimensional source was set to $180 \mathrm{~m}$ in the $\mathrm{E}-\mathrm{W}$ direction. The estimated emission strength ranged between $6.2 \pm 0.18 \mathrm{~kg} \mathrm{~d}^{-1} \mathrm{NH}_{3}$ (FIDES-3D model) and $9.2 \pm 0.7 \mathrm{~kg} \mathrm{~d}^{-1} \mathrm{NH}_{3}$ (Gaussian model). These estimates were $94 \%$ and $66 \%$ of what was obtained using emission factors from the German national inventory (9.6 $\mathrm{kg} \mathrm{d}^{-1} \mathrm{NH}_{3}$ ) as shown in Hensen et al. (2009).

The local advection fluxes were estimated at Site 1 and Site 2, where vertical $\mathrm{NH}_{3}$ fluxes and concentration were also measured and described in Milford et al. (2009). Three periods were considered: (1) before the cut (29 May 2000), when the main local source was the farm buildings and the grassland was a small sink, (2) after the cut but before the fertilisation (5 June 2000), when the main field and the farm buildings were both contributing to local advection, and (3) after fertilisation, when the field was the main contributor to local advection.

\subsection{Micrometeorological measurements}

Micrometeorological measurements were performed at Site 1 and Site 2. These included eddy covariance fluxes measurements, which provided the wind direction $\left(W_{d}\right)$, the friction velocity $\left(u_{*}\right)$, the Monin-Obukhov length $(L)$, and the sensible and latent heat fluxes ( $H$ and $L E$ respectively). Also measured were the air temperature $\left(T_{a}\right)$ and relative 


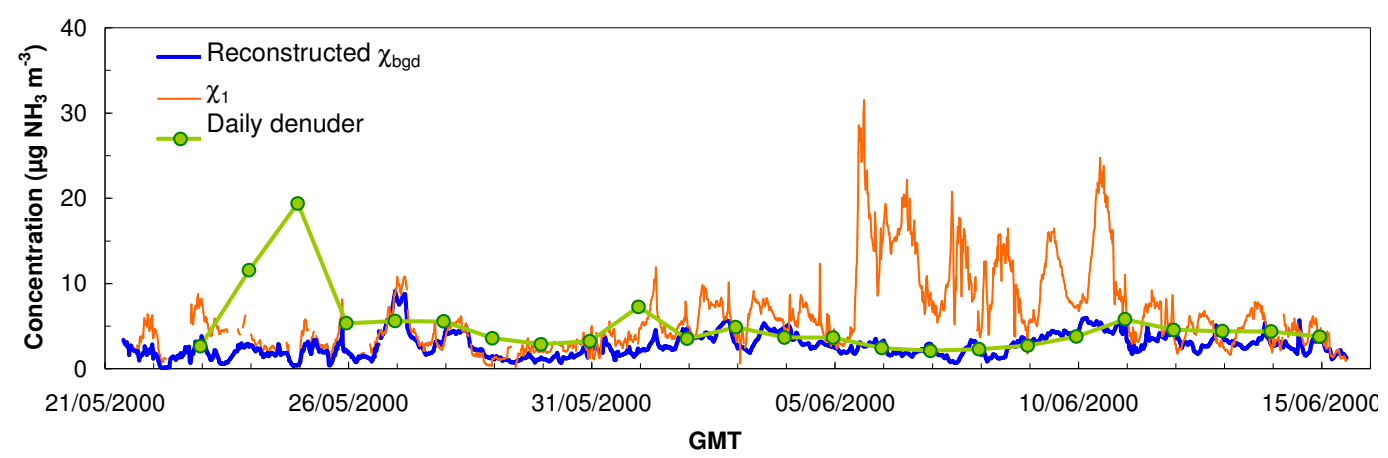

Fig. 2. Background concentration $\left(\chi_{\mathrm{bgd}}\right)$ as measured with a batch denuder at Site $6(800 \mathrm{~m}$ E-NE of Site 1$)$, at $42 \mathrm{~m}$ height, compared with a daily denuder at grass field II (400-600 $\mathrm{m} \mathrm{N}$ of Site 3), and the concentration at Site $1\left(\chi_{1}\right)$. Since before the 15:00 GMT 26 May the background concentration was not available, and was reconstructed using the concentration at Site 2 ( $810 \mathrm{~m}$ downwind from the farm).

humidity $(R H)$, as well as the global and net radiation $\left(S_{t}\right.$ and $R_{n}$ respectively). All these data were measured with replication, which allowed a consensus micrometeorological database to be established for the whole experimental field. Using the measured fluxes, $T_{a}, u$ and $R H$ were estimated at a reference height of $1 \mathrm{~m}$ above $d$. In the modelling approach, $u_{*}$ and $L$ were filtered to consider only data where: $u_{*}>0.2 \mathrm{~m} \mathrm{~s}^{-1}$ and $|L|>5 \mathrm{~m}$. The roughness height $\left(z_{0}\right)$ and the displacement height (d) were both estimated using a wind speed profile and retrieving $d$ by minimising the linear regression between $u(z)$ and $\ln (z-d)$. The roughness height $z_{0}$ was estimated using measured $u_{*}$ and wind speed profile, knowing $d$ (Nemitz et al., 2009b).

\subsection{Ammonia concentration and fluxes measurements}

$\mathrm{NH}_{3}$ concentration was measured at four locations (Fig. 1). Three AMANDA analysers (Wyers et al., 1993) situated at Site 3 in a North-South line provided $\mathrm{NH}_{3}$ concentration on a 30 min averaging period. At Site $1, \mathrm{NH}_{3}$ concentration was measured with two AMANDA gradient systems and a miniWEDD system giving quarterly-hourly vertical $\mathrm{NH}_{3}$ fluxes and concentration at $1 \mathrm{~m}$ height. Four REA systems were also present at Site 1, which provided the flux at a height of $2.1 \mathrm{~m}$ above ground (Hensen et al., 2008). At Site 2 fluxes and concentration were measured with a single AMANDA gradient system (Milford et al., 2009). The background concentration $\left(\chi_{\text {bgd }}\right)$ was measured with an automatic batch denuder system (Keuken et al., 1988), located at $42 \mathrm{~m}$ height near the top of a tower (Site 6, located $950 \mathrm{~m}$ to the E-NE of Site 1). In addition, daily concentrations were measured in grassland Field II (Fig. 1) at $400-600 \mathrm{~m}$ to the $\mathrm{N}$ of the main field, as part of a long-term denuder monitoring. Measurements were initiated at Site 6 on 26 May 2000, therefore before this date the background concentration was assumed to be equivalent to that at Site 2. This implies that advection errors are assumed to be zero at Site 2 before this time. Mean and standard deviation of the $\mathrm{NH}_{3}$ concentration was estimated for Site 1 and Site 3 over the three measurement systems. The concentration at each site $i$ is referred to as $\chi_{i}$ in the following. As a quality control, unknown standard aqueous $\mathrm{NH}_{4}^{+}$samples were distributed and measured by all the $\mathrm{NH}_{3}$ analysers (Milford et al., 2009).

The background concentration $\left(\chi_{\mathrm{bgd}}\right)$ was found to be close to the daily denuder measurements performed 400 $600 \mathrm{~m}$ north of the field, except for the days immediately following the application of manure to grassland Field II (24 and 25 May 2000), and to a smaller extent during the following 10 days (Figure 2). On 24 and 25 May 2000, the main source influencing local advection errors was therefore assumed to be the grassland Field II rather than the farm. The difference between $\chi_{\text {bgd }}$ and $\chi_{1}$ is consistent with the differences in field management. Indeed, almost no difference between $\chi_{1}$ and $\chi_{\text {bgd }}$ was observed before the cut (occurring the 29 May 2000), a small enhancement in $\chi_{1}$ was observed after the cut, while a much larger enhancement occurred after the fertilisation (5 June 2000), which lasted approximately six days.

\subsection{Inferred advection error $\Delta F_{\mathrm{z}, \mathrm{adv}}$ from measured horizontal concentration gradients}

The inferred advection error was assessed with a simplified equation derived from Eq. (2): Assuming logarithmic profiles for $u(z)$ and $\chi_{\mathrm{a}}(z)$ (neutral case), and assuming that the surface concentration in the grassland field is constant (which is equivalent to a compensation point hypothesis), integration of Eq. (2) after some manipulations, leads to :

$$
\begin{aligned}
& \Delta F_{\text {Z,adv }}(x, z)=-u(z) \frac{\partial \chi_{a}(z)}{\partial x} z \times \operatorname{corr}\left(z, z_{0}\right) \\
& \operatorname{corr}\left(z, z_{0}\right)=\left(1-\frac{2}{\ln \left(\frac{z-d}{z_{0}}\right)}+\frac{2}{\ln \left(\frac{z-d}{z_{0}}\right)^{2}}\right) \\
& u(z)=\frac{u_{*}}{k} \ln \left(\frac{z-d}{z_{0}}\right) \\
& \chi_{a}(z)=\chi_{o}+\frac{\chi_{*}}{k} \ln \left(\frac{z-d}{z_{0}}\right)
\end{aligned}
$$

where $\chi_{o}$ is $\chi_{\mathrm{a}}\left(z_{0}\right)$ and $\chi_{*}=\partial \chi_{a} / \partial \ln (z)$. Taking $z-d=1 \mathrm{~m}$ and $z_{0}=0.04 \mathrm{~m}$ (which is the median value of $z_{0}$ in this study), the 
correction factor $\operatorname{corr}\left(z, z_{0}\right) \sim 0.57$. Equation (3) was used in this study to estimate $\Delta F_{\mathrm{z}, \text { adv }}(x, z)$ using measured wind speed at $1 \mathrm{~m}$ height at Site 1 and horizontal concentration gradient $\partial \chi_{\mathrm{a}}(x, z) / \partial x$ estimated as the slope of the linear or log-normal regression between $\chi_{a}$ and $x$ at sites 1, 2 and 3 . Note that although Eq. (3) is derived for neutral conditions, it was used for all conditions.

Two wind-sectors were retained: $245<W D<285$, for westerly winds, and $65<W D<105$ for easterly winds. The advection error at $1 \mathrm{~m}$ height was either positive when the horizontal gradient was negative, due to an advective plume coming from the farm, or positive (positive horizontal gradient) due to field emissions of $\mathrm{NH}_{3}$.

\subsection{Inferred advection error $\Delta \mathbf{F}_{z, a d v}$ using a dispersion modelling approach}

An alternative approach to estimate advection errors is based on the use of a two dimensional (2-D) dispersion model to infer the sources from measured concentration at several locations. This provides a means to constrain the advection flux estimates, as well as a way to estimate the spatial evolution of the advection fluxes with more details than measurementbased estimates. The modelling approach is based on the use of the general superposition principle (Raupach, 1989; Thomson, 1987), which relates the concentration at a location $(x, z), \chi_{\mathrm{a}}(x, z)$, to the source strength at another location $\left(x_{\mathrm{s}}, z_{\mathrm{s}}\right), S\left(x_{\mathrm{s}}, z_{\mathrm{s}}\right)$, with the use of a dispersion function $D\left(x, z / x_{\mathrm{s}}, z_{\mathrm{s}}\right)\left(\right.$ in $\left.\mathrm{s} \mathrm{m}^{-3}\right)$ :

$\chi_{\mathrm{a}}(x, z)=\chi_{\mathrm{bgd}}+\int_{\mathrm{all} x_{\mathrm{s}}} S\left(x_{\mathrm{s}}, z_{\mathrm{s}}\right) D\left(x, z / x_{\mathrm{s}}, z_{\mathrm{s}}\right) \mathrm{d} x_{\mathrm{s}}$

where $\chi_{\text {bgd }}$ is the background concentration, assumed to be constant with height. $D\left(x, z / x_{\mathrm{s}}, z_{\mathrm{s}}\right)$ was estimated using the Green's approach to solve the two-dimensional advectiondiffusion equation, based on the assumptions of power law functions to describe the wind speed $u(z)$ and the vertical diffusivity $K_{\mathrm{Z}}(z)$ profiles (Huang, 1979; Philip, 1959; Yeh and Huang, 1975). A description of the dispersion model and a discussion about its quality and defaults is given in Loubet et al. (2001). The combination of Eqs. (2) and (4) gives the advection flux $\Delta F_{\mathrm{z}, \text { adv }}(x, z)$ once the sources $S\left(x_{\mathrm{s}}, z_{\mathrm{s}}\right)$ and the dispersion matrix are known. Note that $\Delta F_{z, \text { adv }}(x, z)$ is independent of $\chi_{\mathrm{bgd}}$ since it is a function of $\partial \chi_{\mathrm{a}}(x, z) / \partial x$. In this study, $S\left(x_{\mathrm{s}}, z_{\mathrm{s}}\right)$ was used as a fitting parameter to minimise the difference between measured and modelled concentration at several distances. Details of the determination of $S\left(x_{\mathrm{s}}, z_{\mathrm{s}}\right)$ (its location and heterogeneity), as well as the fitting procedure are provided in the following sections.

On the basis of Eqs. (2) and (4), the advection error $\Delta F_{\mathrm{Z}, \text { adv }}$ at $1 \mathrm{~m}$ height at Site 1 was estimated as the superposition of the advection error due to the farm and the advection error due to the experimental field itself. The FIDES-2D model (Flux Interpretation by Dispersion and Exchange over Short-range, in 2 Dimensions) (Loubet et al., 2001) was used to infer the emission strength from the source $\left(S_{\text {src }}\right)$, using $\chi_{3}$ and $\chi_{\mathrm{bgd}}$. For modelling purposes, the farm source was considered to be infinitely long in $y$ and $180 \mathrm{~m}$ wide in $x$, and located at $x=230 \mathrm{~m}$ upwind of site 3 (III in Fig. 1). No $\mathrm{NH}_{3}$ surface exchange was considered in the fields located between the farm and the Field I, unless otherwise stated. As FIDES2D applies to homogeneous fields, a single $z_{0}$ and a single $d$ was considered for the whole distance downwind from the source, which were either taken from the micrometeorological dataset (Nemitz et al., 2009b) when modelling advection errors from the field, or fixed to $z_{0}=0.1 \mathrm{~m}$ and $d=0.5 \mathrm{~m}$ when modelling advections errors from the farm, since taller canopies and heterogeneities were present between the farm and the field.

Using the FIDES-2D model, the $\mathrm{NH}_{3}$ surface flux $S_{\text {field }}$ was estimated in the experimental field (Kleinkamp in Fig. 1) using $\chi_{3}$ as $\chi_{\mathrm{bgd}}$ to take account of the enhancement of concentration at the entry of the field due to farm emissions. Two hypotheses were compared: (H1) $S_{\text {field }}$ was considered constant over the whole field, and (H2) the canopy compensation point concentration $\chi_{c}$ (e.g., Sutton et al., 1995) was considered constant over the whole field, which implies a nonhomogeneous $S_{\text {field }}$. The second hypothesis $\mathrm{H} 2$ is based upon the compensation point approach, which relates $S_{\text {field }}$ to $\chi_{\mathrm{c}}$ by the following relationship: $S_{\text {field }}=-\left(\chi_{\text {surf }}-\chi_{\mathrm{c}}\right) / R_{\mathrm{b}}$ where $\chi_{\text {surf }}$ is the concentration at $z_{0}$, and $R_{b}$ is the canopy excess resistance, estimated using the expression of Garland (1977). Under H1, $S_{\text {field }}$ was tuned in order for the modelled and measured concentration $\chi_{1}$ to fit, whereas under $\mathrm{H} 2, \chi_{\mathrm{c}}$ was tuned instead of $S_{\text {field }}$. Since FIDES-2D is a 2-D model, the equivalent field size upwind of Site 1 was assumed to be equal to the fetch between the side of the field and Site 1 for a given wind direction.

\section{Results}

\subsection{Concentration enhancement due to the farm and the experimental field}

The background concentration was generally smaller than concentrations measured at the other sites apart from Site $2\left(\chi_{2}\right)$ during some periods (Fig. 3). The latter situation is explained by the fact that the experimental field is a local sink, since $\chi_{2}$ is measured near the ground whereas $\chi_{\mathrm{bgd}}$ is measured at $42 \mathrm{~m}$ height. There was clearly a concentration enhancement at Site 3 during westerly winds before fertilisation (see Fig. 3). The concentration enhancement was the largest when Site 3 was downwind from the farm, which corresponded to wind directions $270-280 \pm 30$ degrees.

After fertilisation $\chi_{1}$ was larger than $\chi_{\text {bgd }}$, which indicated an $\mathrm{NH}_{3}$ emission from the experimental field. A clear difference can be seen between three typical measured horizontal gradients in $\chi_{\mathrm{a}}$ during westerly winds, corresponding to the pre-cut, post-cut and post-fertilisation periods (Fig. 4). 


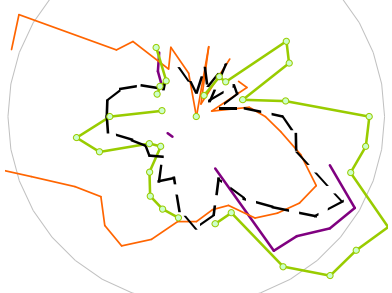

Pre-cut period
10

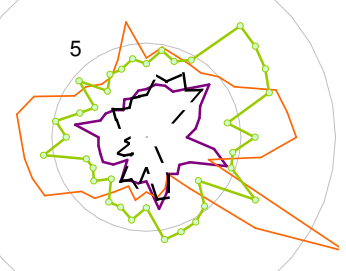

Post-cut period

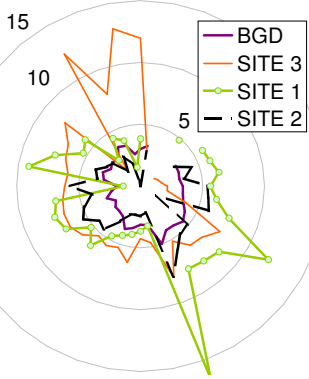

Post-fertilization period

Fig. 3. Concentration rose $\left(\mu \mathrm{g} \mathrm{NH}_{3} \mathrm{~m}^{-3}\right)$, where $\mathrm{NH}_{3}$ concentration at Sites 1,2 and 3 as well as the background concentration (Site 6) is shown. The concentration rose has been calculated with quarterly hourly data, averaged over wind sectors of 10 degrees. All data have been averaged over three common periods: before the cut on the left, after cut in the middle, and after fertilisation on the right.

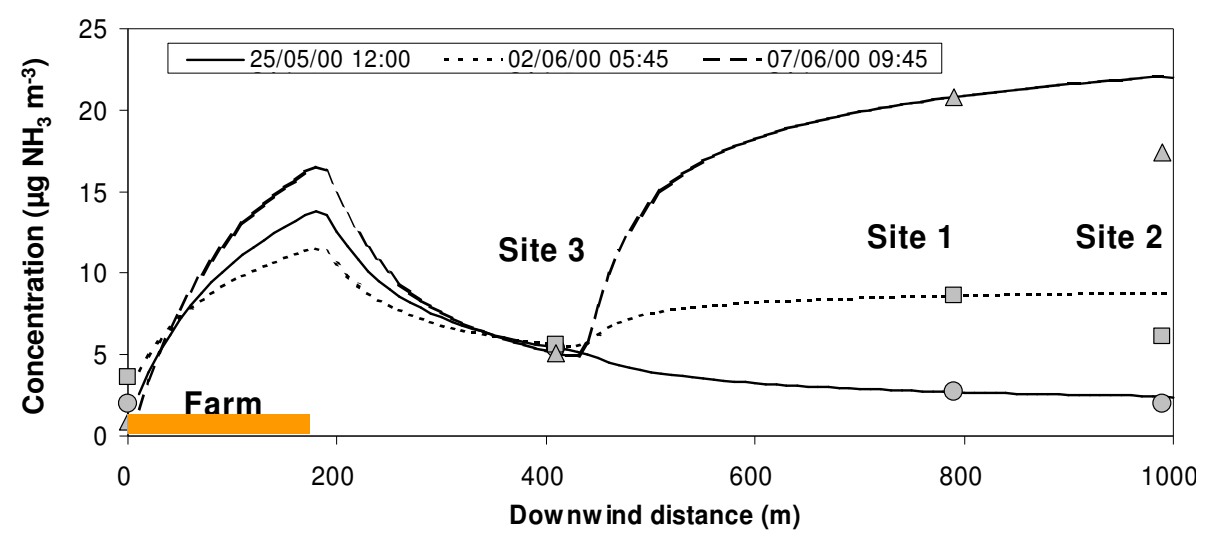

Fig. 4. Example horizontal profile of $\mathrm{NH}_{3}$ concentration. Symbols are measurements at sites 1, 2, 3, as well as the background (shown at $x=0$ ), and lines are the FIDES-2D outputs. Three example runs are shown: during the pre-cut (25 May 2000, 12:00, circles), the postcut ( 2 June 2000, 05:45, squares) and the post-fertilisation periods (7 June 2000, 09:45, triangles). These examples correspond to similar micrometeorological conditions $\left(u_{*}\right.$ and $\left.L\right)$. The farm is located from $x=0$ to $x=180 \mathrm{~m}$.

During the pre-cut period the horizontal concentration gradient was negative whereas it was positive during the post-cut and post-fertilisation periods. After fertilisation, there was always a larger concentration at Site 1 than at Site 2 during westerly winds, which might have been either due to an effect of the trees on the east of the experimental field (e.g. change in wind direction, enhanced turbulence), or the nonhomogeneity of the field as an $\mathrm{NH}_{3}$ emission source.

The FIDES-2D model concentration coincided with the measured concentration at Sites 3 and 1 since these concentrations were used to fit the model (Fig. 4). The three examples in Fig. 4 illustrate that two sources of advection errors (the farm, and the field) combined to either a net positive (25 May) or net negative (2 June and 7 June) advection error, corresponding to a negative or a positive horizontal concentration gradient, respectively (see Eqs. 2 and 3). These results also demonstrate that the mean concentration values used to estimate the inferred advection error $\Delta F_{\mathrm{Z}, \text { adv }}$ on the base of a linear regression between measured concentration and the distance may lead to overestimation of the horizontal concentration gradient at Site 1 as compared to the modelled one.

\subsection{Local advection at site 1}

The time course of the measured flux, the inferred advection error (Eq. 3), and the modelled farm and field advection error at Site 1 demonstrated distinct behaviour during different management periods, shown by the selection of three typical days (Fig. 5) During 27 May 2000 (pre-cut period), the field was a small sink and the positive advection error mainly originated from the farm source. On 7 June 2000 (post-fertilisation), the field was a strong $\mathrm{NH}_{3}$ source and was therefore the main contributor to the advection error, which was negative in this case. During 12 June 2000 (later after fertilisation) a mix of local advection due to a small field source and a farm source was observed, which lead to a small but positive advection error. 

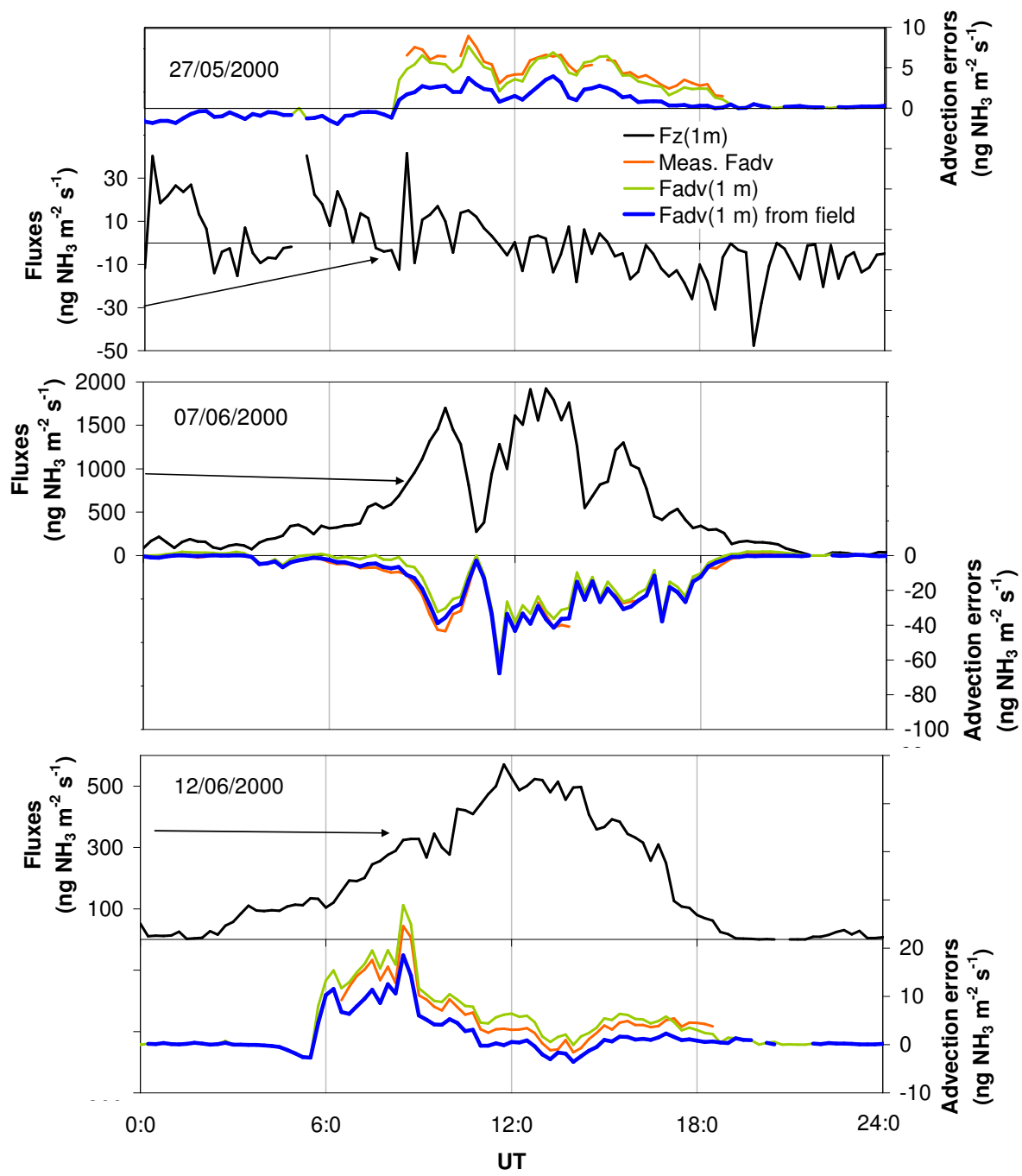

Fig. 5. Advection error $\left(\Delta F_{\mathrm{Z}, \text { adv }}\right)$ at $1 \mathrm{~m}$ height for three typical days, before the cut (27 May 2000), just after fertilisation (7 June 2000$)$ and a week after fertilization (12 June 2000). "Fz" is the measured flux at Site 1, "Meas. Fadv" is the inferred local advection error, "Fadv" is the modelled local advection error at $1 \mathrm{~m}$, including the contribution from the field and the farm, and "Fadv ( $1 \mathrm{~m})$ from field" is the local advection error due to field only. Note the different y-scales. The advection errors from the farm are only given for periods when the wind was in the sector 270 degree \pm 15 degree.

These results demonstrate that the inferred advection error $\Delta F_{\mathrm{Z}, \text { adv }}$ at $1 \mathrm{~m}$ height was systematically larger in magnitude than the modelled one. The contribution of the farm to $\Delta F_{z, a d v}$ at $z=1 \mathrm{~m}$ at Site 1 was bounded between -1 and $17 \mathrm{ng} \mathrm{NH}_{3} \mathrm{~m}^{-2} \mathrm{~s}^{-1}$, and 0 and $27 \mathrm{ng} \mathrm{NH}_{3} \mathrm{~m}^{-2} \mathrm{~s}^{-1}$ for the inferred and modelled advection error, respectively. The contribution from the field itself to advection errors was much more variable, since it was related to the field emissions, which varied from about $-50 \mathrm{ng} \mathrm{NH}_{3} \mathrm{~m}^{-2} \mathrm{~s}^{-1}$ before the cut to more than $3000 \mathrm{ng} \mathrm{NH}_{3} \mathrm{~m}^{-2} \mathrm{~s}^{-1}$ after the fertilization. Maximum advection errors at $z=1 \mathrm{~m}$ due to the field reached -44 and $-32 \mathrm{ng} \mathrm{NH}_{3} \mathrm{~m}^{-2} \mathrm{~s}^{-1}$ on 7 June 2000 , as estimated by inference and modelling, respectively. The modelled $\Delta F_{\mathrm{Z}, \text { adv }}$ at $z=2 \mathrm{~m}$, also shown in Fig. 5 for comparison, was much better correlated with the inferred advection error, especially on 12 June 2000. Advection errors from the field, estimated with hypothesis H1 (constant surface flux) were significantly higher than those estimated with hypothesis $\mathrm{H} 2$ (constant surface concentration). H1 advection errors were from 1.2 to up to 8 times larger than $\mathrm{H} 2$ advection errors. The surface layer thermal stratification was the main driver of the difference between the two estimates (Fig. 6).

Measured $\Delta F_{\mathrm{Z}, \text { adv }}$ at Site 1 represented more than $100 \%$ of the flux at $1 \mathrm{~m}$ height when the flux from the field was small, typically before the cut. Following cutting, the advection errors were smaller on average but on occasion could still represent up to $50 \%$ of the flux as on 30 May 2000, when the emission from the farm was large (see Hensen et al., 2009b). 


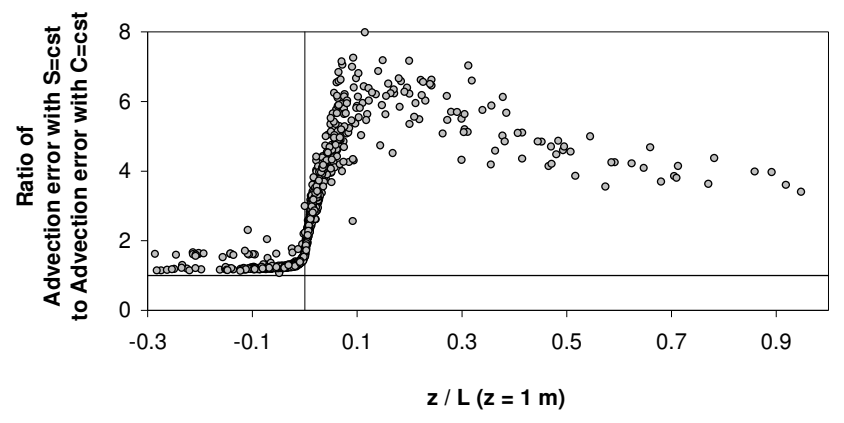

Fig. 6. Ratio of the modelled local advection error estimated with a constant surface source hypothesis $(S=\mathrm{cst}$ ), and a constant surface concentration hypothesis $(C=\mathrm{cst})$, as a function of the stability factor $(z / L)$, where $\mathrm{L}$ is the Monin Obukhov length.

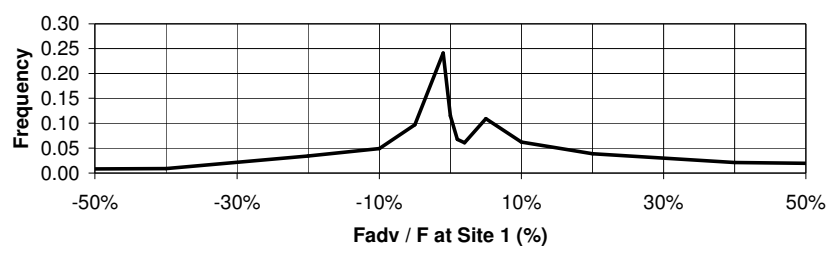

Fig. 7. Distribution of advection errors at Site 1 as estimated with the inference method.

Following fertilisation when the field emissions were large, although the advection errors were large in magnitude, they were typically less than $10 \%$ and averaged less than $2 \%$ of the flux at $1 \mathrm{~m}$. However, a week following fertilisation the advection errors reached again up to $100 \%$ of the flux on 11 June 2000. A summary of the magnitude of advection errors at Site 1 (averaged over model and inferred) is provided in Fig. 7. The integrated distribution shows that for $55 \%$ of the cases the advection error was smaller than $5 \%$, for $18 \%$ of the cases it was larger than $20 \%$ and for $9 \%$ of the cases it was larger than $60 \%$. The median, minimum and maximum values of inferred and modelled advection errors as well as the advection as a percentage of the flux (median) are provided in Table 1. These figures demonstrate that the pre-cut period showed significant advection errors due to the flux at Site 1 being very small. However when the flux at Site 1 increased, the advection error represented on average around 1.4 to $2.1 \%$ of the flux.

\section{Discussion}

\subsection{Comparison of modelled and inferred advection er- rors}

The Braunschweig experiment provided the opportunity to validate the inverse modelling approach developed by Loubet et al. (2001) to infer the advection errors, by comparing with the direct estimates of advection errors from the measured

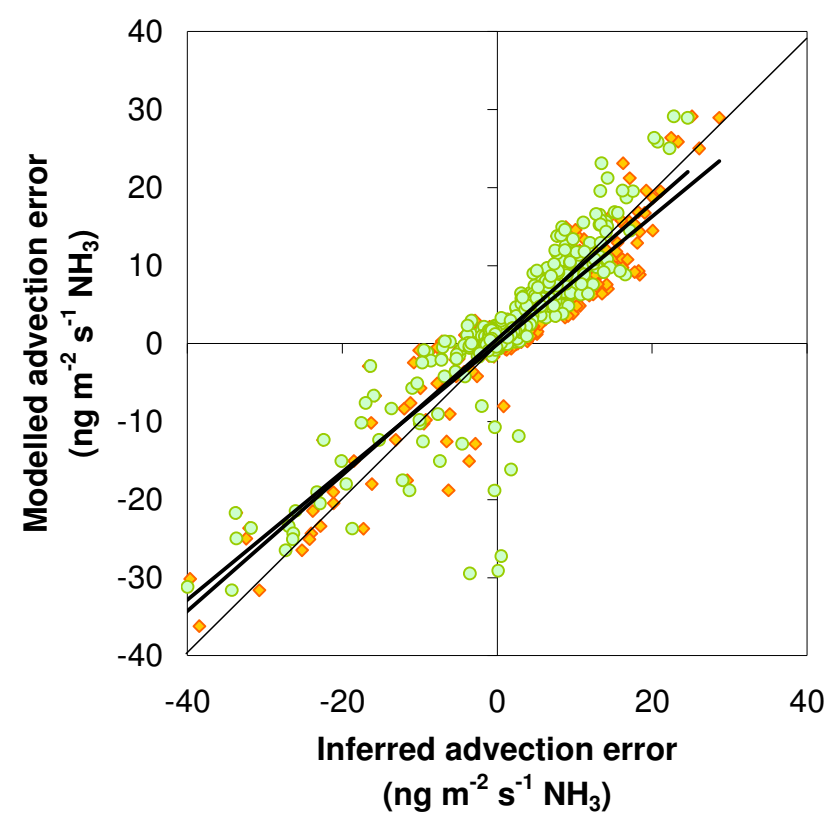

Fig. 8. Modelled versus inferred local advection error $\left(\Delta F_{\mathrm{z}, \mathrm{adv}}\right)$ at $z=1 \mathrm{~m}$ and Site 1 , estimated assuming a linear (orange diamonds) and a logarithmic (green circles) horizontal concentration profile. A linear regression between modelled and inferred local advection errors gives $y=0.82 x-0.09\left(R^{2}=0.88\right)$ and $y=0.87 x+0.6\left(R^{2}=0.76\right)$, for linear and logarithmic horizontal profiles assumptions, respectively.

horizontal concentration gradient. The agreement was good between the measured and modelled $\Delta F_{\mathrm{z} \text {,adv }}$ at $1 \mathrm{~m}$ height, as shown for selected days (Fig. 5) and for the whole period (Fig. 8). The model underestimates the inferred $\Delta F_{\mathrm{z} \text {,adv }}$ by $17 \%$ and $13 \%$ on average assuming a linear and a logarithmic horizontal profile, respectively. In other terms, the logarithmic horizontal profile assumption leads roughly to a $20 \%$ reduction in the inferred advection error at Site 1, which is expected as a logarithmic horizontal profile gives smaller gradient than the linear horizontal profile for large distances (larger than a few tens of meters).

The choice of the surface source also has an impact on the modelled advection error. Indeed with a "constant surface source" ( $S=$ cst) assumption the model systematically gives larger values than with the "constant concentration source" $\left(C_{\mathrm{s}}=\mathrm{cst}\right)$ assumption (1.3 times larger under unstable conditions to more than 6 times larger under stable conditions) (Fig. 6). This is expected since a "constant concentration source" leads to a rapid decrease of the source strength with distance due to the enrichment of the surface concentration. This effect is larger for stable conditions for which the turbulent dilution is limited and the "constant concentration sources" tends to "vanish". A summary of the effect of the hypotheses " $C_{\mathrm{s}}=$ cst" and " $S=$ cst" on the advection error due to emissions from the field is given in Table 2. These results 
Table 1. Local advection error during four periods: the pre-cut (22 May-29 May), post-cut (29 May-5 June), post-fertilisation (5 June-11 June) and 7 days after fertilisation (11 June-16 June). $F_{\mathrm{Z}}$ (Site 1$)$ is the measured vertical flux at $z=1 \mathrm{~m}$ at Site $1, \Delta F_{\mathrm{Z}, \text { adv }}\{$ inferred $\}$ is the inferred advection error using Eq. (3), $\Delta F_{\mathrm{Z}, \text { adv }}\{$ farm $\}$ and $\Delta F_{\mathrm{Z}, \text { adv }}\{$ field $\}$ are modelled advection errors at $z=1 \mathrm{~m}$ due to the farm and the experimental field respectively. Also given is the ratio of $\Delta F_{\mathrm{Z}, \text { adv }}$ to $F_{\mathrm{Z}}$ at Site 1 as inferred, or modelled assuming only a field or a farm contribution.

\begin{tabular}{|c|c|c|c|c|c|c|c|c|}
\hline \multirow[t]{2}{*}{ Period } & \multirow[t]{2}{*}{$\begin{array}{l}F_{\mathrm{Z}}(\text { Site } 1) \\
\mathrm{ng} \mathrm{NH} \mathrm{m}_{3} \mathrm{~m}^{-2} \mathrm{~s}^{-1}\end{array}$} & \multirow[t]{2}{*}{$\begin{array}{l}\Delta F_{\text {Z,adv }}\{\text { Inferred }\} \text { Site } 1 \\
\text { ng NH} \mathrm{m}^{-2} \mathrm{~s}^{-1}\end{array}$} & \multirow[t]{2}{*}{$\begin{array}{l}\Delta F_{\mathrm{z}, \text { adv }}\{\text { Inferred }\} \text { Site } 2 \\
\mathrm{ng} \mathrm{NH} \mathrm{m}^{-2} \mathrm{~s}^{-1}\end{array}$} & \multirow[t]{2}{*}{$\begin{array}{l}\Delta F_{\mathrm{z}, \text { adv }}\{\text { farm }\} \text { Site } 1 \\
\mathrm{ng} \mathrm{NH} \mathrm{m}^{-2} \mathrm{~s}^{-1}\end{array}$} & \multirow[t]{2}{*}{$\begin{array}{l}\Delta F_{\mathrm{Z}, \text { adv }}\{\text { field }\} \text { Site } 1 \\
\mathrm{ng} \mathrm{NH}_{3} \mathrm{~m}^{-2} \mathrm{~s}^{-1}\end{array}$} & \multicolumn{3}{|c|}{$\begin{array}{c}\mid \Delta F_{\mathrm{Z}, \text { adv }}\{\text { Site } 1\} \mid / F_{\mathrm{Z}} \text { (Site1) } \\
\%\end{array}$} \\
\hline & & & & & & inferred & farm & Field \\
\hline Pre-cut & $-4[-57 ; 51]$ & $6.3[-0.8 ; 17]$ & $4.7[-0.6 ; 13]$ & $2.8[0.2 ; 26.6]$ & $0.0[-10.4 ; 8.8]$ & $52 \%$ & $32 \%$ & $6.8 \%$ \\
\hline Post-cut & $61[-106 ; 641]$ & $4.5[-3.5 ; 23]$ & $3.4[-2.7 ; 17]$ & $2.2[-0.4 ; 8.5]$ & $-0.4[-187 ; 21]$ & $4 \%$ & $3 \%$ & $3.7 \%$ \\
\hline Post-fert. & $430[1 ; 3638]$ & $-1.6[-44 ; 16]$ & $-1.2[-32 ; 12]$ & $2.5[-2.3 ; 8.8]$ & $-4.8[-209 ; 13]$ & $1.4 \%$ & $0.7 \%$ & $1.5 \%$ \\
\hline $7 \mathrm{~d}$ later & $91[-6 ; 571]$ & $3.2[-3 ; 25]$ & $2.4[-2 ; 18]$ & $3.4[-1.7 ; 10.7]$ & $0.1[-24 ; 35]$ & $2.1 \%$ & $1.5 \%$ & $1.6 \%$ \\
\hline
\end{tabular}

Table 2. Summary of local advection errors $\Delta F_{\mathrm{Z}, \text { adv }}$ due to farm or field emissions as estimated with FIDES-2D. The farm is an infinitely wide farm emitting $100 \mu \mathrm{g} \mathrm{NH}_{3} \mathrm{~m}^{-1} \mathrm{~s}^{-1}$ (2-D hypothesis). Distance is the downwind distance from the downwind edge of the farm, fetch is the upwind fetch in the field, and " $\mathrm{C}$ cst" stands for constant concentration field emission hypothesis, while "S cst" stands for constant surface flux emission hypothesis.

\begin{tabular}{|c|c|c|c|c|c|c|c|c|}
\hline \multirow[b]{2}{*}{$u_{*}$} & \multirow[b]{2}{*}{$z_{0}$} & \multirow[b]{2}{*}{$L$} & \multicolumn{3}{|c|}{ Advection from Farm } & \multicolumn{3}{|c|}{ Advection due to field emissions } \\
\hline & & & distance & $\Delta F_{\mathrm{Z}, \mathrm{adv}}$ & $\Delta F_{\mathrm{Z}, \mathrm{adv}}$ & fetch & $\begin{array}{l}\Delta F_{\mathrm{Z}, \mathrm{adv}} \\
\mathrm{C} \mathrm{cst}\end{array}$ & $\begin{array}{l}\Delta F_{\mathrm{Z}, \mathrm{adv}} \\
\underline{\mathrm{S} \mathrm{cst}}\end{array}$ \\
\hline $\mathrm{ms}^{-1}$ & $\mathrm{~mm}$ & $\mathrm{~m}$ & $\mathrm{~m}$ & $\mathrm{ng} \mathrm{NH} \mathrm{m}_{3} \mathrm{~m}^{-2}$ & $\%$ (source) & $\mathrm{m}$ & $\%$ (source) & $\%$ (source) \\
\hline 0.10 & 100 & $\inf$ & 300 & 7.2 & $0.72 \%$ & 100 & $-3.9 \%$ & $-6.9 \%$ \\
\hline 0.30 & 100 & inf & 300 & 7.2 & $0.72 \%$ & 100 & $-4.1 \%$ & $-6.9 \%$ \\
\hline 0.60 & 100 & $\inf$ & 300 & 7.2 & $0.72 \%$ & 100 & $-4.3 \%$ & $-6.9 \%$ \\
\hline 0.80 & 100 & $\inf$ & 300 & 7.2 & $0.720 \%$ & 100 & $-4.4 \%$ & $-6.9 \%$ \\
\hline 0.30 & 10 & $\inf$ & 300 & 15.2 & $1.52 \%$ & 100 & $-11.2 \%$ & $-16.3 \%$ \\
\hline 0.30 & 100 & $\inf$ & 300 & 7.2 & $0.72 \%$ & 100 & $-4.1 \%$ & $-6.9 \%$ \\
\hline 0.30 & 1000 & $\inf$ & 300 & 1.7 & $0.17 \%$ & 100 & $-0.9 \%$ & $-1.3 \%$ \\
\hline 0.30 & 100 & -10 & 300 & 4.4 & $0.44 \%$ & 100 & $-2.7 \%$ & $-4.3 \%$ \\
\hline 0.30 & 100 & -1 & 300 & 4.4 & $0.44 \%$ & 100 & $-1.1 \%$ & $-1.6 \%$ \\
\hline 0.30 & 100 & 1 & 300 & 9.5 & $0.95 \%$ & 100 & $-28.4 \%$ & $-50.0 \%$ \\
\hline 0.30 & 100 & 10 & 300 & 9.5 & $0.95 \%$ & 100 & $-6.6 \%$ & $-12.4 \%$ \\
\hline 0.30 & 100 & inf & 50 & 93.1 & $9.31 \%$ & 30 & $-14.5 \%$ & $-20.1 \%$ \\
\hline 0.30 & 100 & $\inf$ & 100 & 39.1 & $3.91 \%$ & 50 & $-8.6 \%$ & $-13.0 \%$ \\
\hline 0.30 & 100 & $\inf$ & 200 & 14.0 & $1.40 \%$ & 100 & $-4.1 \%$ & $-6.9 \%$ \\
\hline 0.30 & 100 & $\inf$ & 300 & 7.2 & $0.72 \%$ & 200 & $-2.0 \%$ & $-3.6 \%$ \\
\hline 0.30 & 100 & $\inf$ & 500 & 3.0 & $0.30 \%$ & 400 & $-0.9 \%$ & $-1.8 \%$ \\
\hline 0.30 & 100 & $\inf$ & 1000 & 0.8 & $0.08 \%$ & 1000 & $-0.4 \%$ & $-0.8 \%$ \\
\hline
\end{tabular}

show that the " $S=$ cst" hypothesis gives advection errors from 1.4 to 2.1 times smaller than " $C_{\mathrm{s}}=\mathrm{cst}$ " for a range of usual conditions. It can be concluded that "constant concentration sources" such as volatilisation processes are less subject to local advection errors than "constant surface sources" such as biogenic emission processes $\left(\mathrm{N}_{2} \mathrm{O}, \mathrm{NO}, \mathrm{CH}_{4}, \mathrm{CO}_{2}\right.$ respiration).

Using the standard error of measured $\mathrm{NH}_{3}$ concentrations (14.8\%) based on Milford et al. (2009), we evaluated the effect on the inferred advection error. The average error on the inferred advection error was found to be $52 \%$, and was smaller $(<21 \%)$ when the fluxes from the field were small (before the fertilisation) and larger following fertilisation (up to $80 \%$ ). These uncertainties are quite large, reflecting the fact that the standard error on the measured concentrations were large (14.8\%), and that there was only three points used in the horizontal concentration profile.

\subsection{2-D versus 3-D estimations of the advection error}

We have used here a 2-D model (FIDES), because firstly in a 2-D approach it is simpler to couple the atmospheric dispersion with a compensation point approach, and secondly we had a horizontal gradient of concentration in one direction only, allowing inferring the advection errors in a 2-D context only. However, it is necessary to evaluate the limits of the 2-D approach for estimating the advection errors in the context of this experiment. As already stated in the 


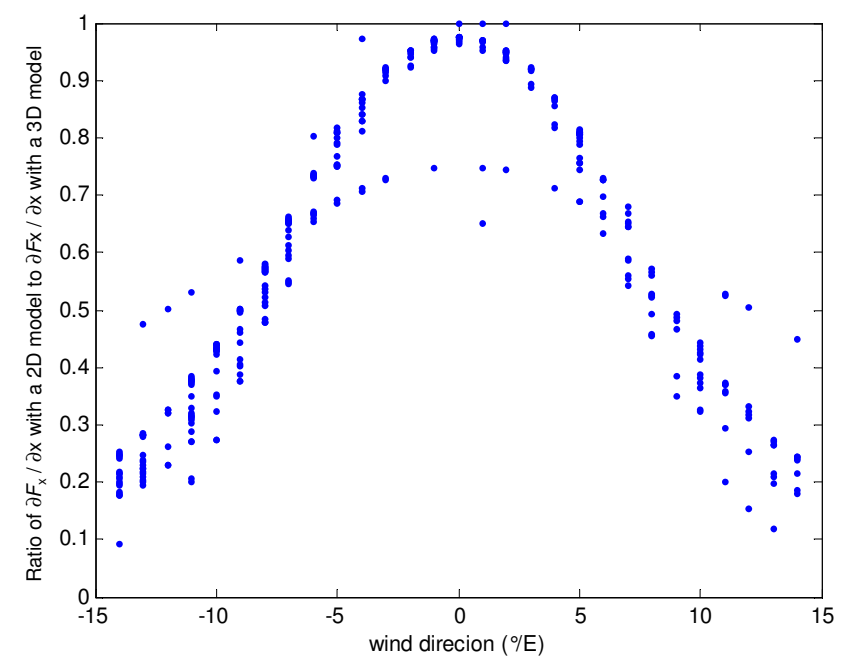

Fig. 9. Ratio of $\partial F_{\mathrm{X}} / \partial x$ evaluated with a 2-D model to that obtained with a 3-D model at $610 \mathrm{~m}$ downwind from the farm source (Site 1 in Fig. 1) as a function of wind direction. Each dot corresponds to a $30 \mathrm{~min}$ data point.

materials and methods section, there are two potential biases when using a 2-D model: first to neglect $\partial F_{\mathrm{y}} / \partial y$ and second to underestimate $\partial F_{\mathrm{x}} / \partial x$ with a 2-D model which does not account for the extra dilution due to lateral dispersion. A third bias may come from an underestimation of the inferred farm source with a 2-D model, but Hensen et al. (2009b) have already shown that in this study the 2-D model gave similar estimates as a 3-D model because of the small number of unstable situations.

Using the 3-D dispersion model of Huang (1979), which is based on the same approach as FIDES-2D, we evaluated both the magnitude of $\partial F_{\mathrm{y}} / \partial y$ and the values of $\partial F_{\mathrm{x}} / \partial x$ as modelled with the 2-D and the 3-D model. We found that:

- far away from the source (farm emissions): $\partial F_{\mathrm{y}} / \partial y$ was negligible against $\partial F_{\mathrm{X}} / \partial x$ (at Site 1 at $610 \mathrm{~m}$ downwind from the source, $\partial F_{\mathrm{y}} / \partial y<0.03 \times \partial F_{\mathrm{x}} / \partial x$ ), while $\partial F_{\mathrm{x}} / \partial x$ estimated with the 2-D model was underestimated as soon as the wind direction was not aligned with the farm (see Fig. 9).

- closer to the source (field emission or deposition): $\partial F_{\mathrm{y}} / \partial y$ was larger and represented $12 \%$ (median) of $\partial F_{\mathrm{X}} / \partial x$ in this experiment, while $\partial F_{\mathrm{X}} / \partial x$ estimated with the 2-D model and the 3-D models were equal.

Hence we see that using a 2-D model for estimating the advection error of a non-infinitely wide source leads to potential underestimation of $\partial F_{\mathrm{x}} / \partial x$ which is small when the wind direction is within $5^{\circ}$ from the source but which severely increase when the wind direction is larger. For field emission/deposition induced advection errors, the lateral flux divergence $\partial F_{\mathrm{y}} / \partial y$ should be taken into account in future work.

\subsection{Magnitude of advection errors}

The median and range of the different advection errors at $1 \mathrm{~m}$ height, in comparison with the measured vertical flux at the same height demonstrated the varying behaviour of the advection error in relation to the flux during the different management periods (Table 1). The advection error due to farm emissions was typically rather small at Site 1 (median 2.2$3.4 \mathrm{ng} \mathrm{NH}_{3} \mathrm{~m}^{-2} \mathrm{~s}^{-1}$ from model estimates). However, before the cut, the advection error due to the farm represented a significant fraction of the flux (32\% based on modelling, 52\% based on inference method). This proportion reduced to $3 \%$ during the post-cut period and was less than $1.5 \%$ after fertilisation. Since $\Delta F_{\mathrm{Z}, \text { adv }}$ due to the farm is always positive, and since it is associated with a negative concentration gradient in the horizontal (Eq. 3), $\mathrm{NH}_{3}$ deposition fluxes are underestimated, and, conversely emissions are over-estimated by the percentage given above.

The magnitude of the advection error from the farm diminished with distance: at Site $2(810 \mathrm{~m}$ downwind of the farm), the modelled advection errors due to the farm were on average $60 \%$ smaller than at Site 1 (610 $\mathrm{m}$ from the farm). The inferred advection error at Site 2 using the logarithmic regression was simply equal to that at Site 1 times the ratio $x\{$ Site 1$\} / x$ \{Site 2$\}$, which gave $610 / 820=0.74$. Hence the inferred advection error at Site 2 was $26 \%$ smaller than that at Site 1 , based on a logarithmic regression.

The advection error due to the field itself was a rather constant fraction of about $1.5 \%$ of the surface flux $F_{\mathrm{Z}}$ (Site 1). In magnitude this can however represent quite a large flux (measured $\Delta F_{\mathrm{Z} \text {,adv }}$ up to $-90 \mathrm{ng} \mathrm{NH}_{3} \mathrm{~m}^{-2} \mathrm{~s}^{-1}$, on 7 June 2000).

This study as well as Loubet et al. (2001) and Milford et al. (2001a) show that advection errors can represent a large fraction of the flux (here up to 52\%) when measuring small $\mathrm{NH}_{3}$ fluxes at distances typically smaller than $400 \mathrm{~m}$ downwind of intensive sources such as farms and intensively grazed fields. Advection errors due to the field on which measurements are performed are usually not taken into account, except through a fetch limitation threshold. For species having heterogeneous sources and sinks like $\mathrm{NH}_{3}$ (Dragosits et al., 1998), $\mathrm{N}_{2} \mathrm{O}$ (Laville et al., 1999), but also water vapour above watered crops under arid climate (Itier et al., 1994), these advection errors may be large, especially if the fetch is smaller than the one encountered here. The decrease of the modelled advection error due to both the farm and the field as a function of the fetch for the same three typical runs as in Fig. 4 (pre-cut, post-cut, and post-fertilisation) is shown in Fig. 10. It can be seen that the local advection error at $1 \mathrm{~m}$ height represented the largest fraction of $F_{\mathrm{z}}$ at a fetch of approximately $30 \mathrm{~m}$, and thereafter decreased. At $x=100 \mathrm{~m}$ the advection error ranged between $3 \%$ and $15 \%$ of the flux and at $x=200 \mathrm{~m}$ it ranged from $1.5 \%$ to $8 \%$ of the flux at $1 \mathrm{~m}$. Further sensitivity analysis with FIDES-2D has shown that the distance at which the advection error at $1 \mathrm{~m}$ is maximum and the rate of decrease both depend upon the 


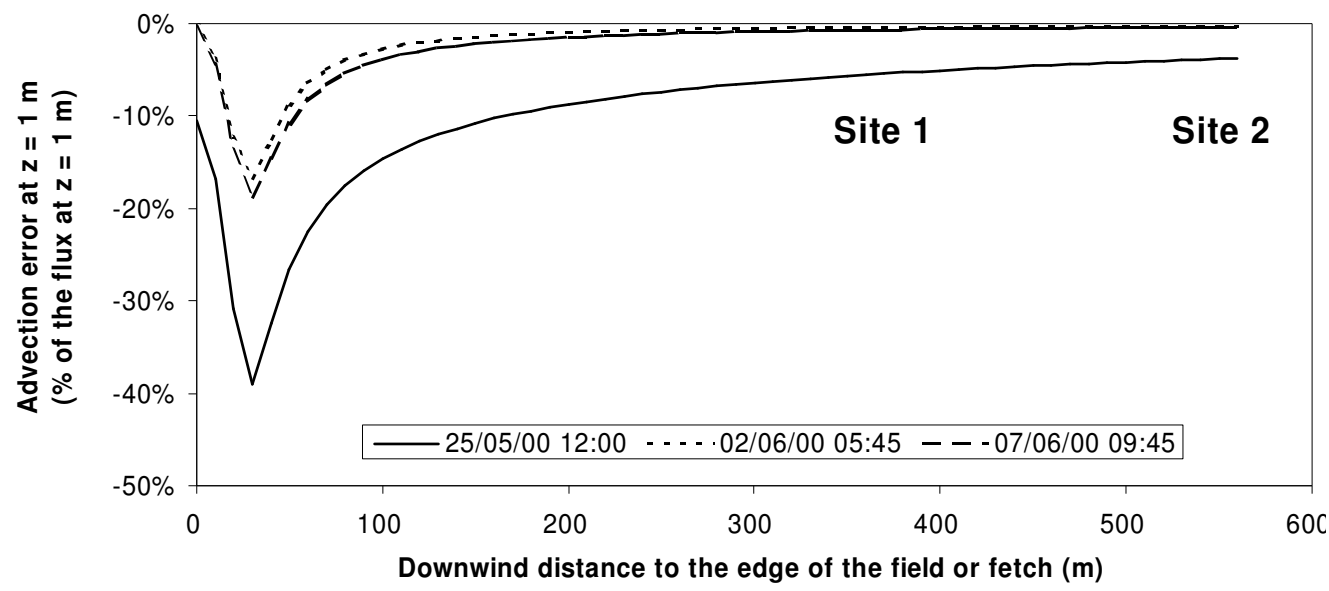

Fig. 10. Ratio of local advection error to flux at $z=1 \mathrm{~m}$, as a function of distance downwind of the edge of the field (fetch) for the same three runs as in Fig. 4, covering the pre-cut (25 May 2000, 12:00), post-cut (2 June 2000, 05:45) and post-fertilisation periods (7 June 2000 , 09:45). Note that the ratio is always negative but the vertical flux was negative (deposition) the 25 May, 12:00, whereas it was positive for the two other situations, while in the same time the local advection error was positive the 25 May and negative for the two other situations.
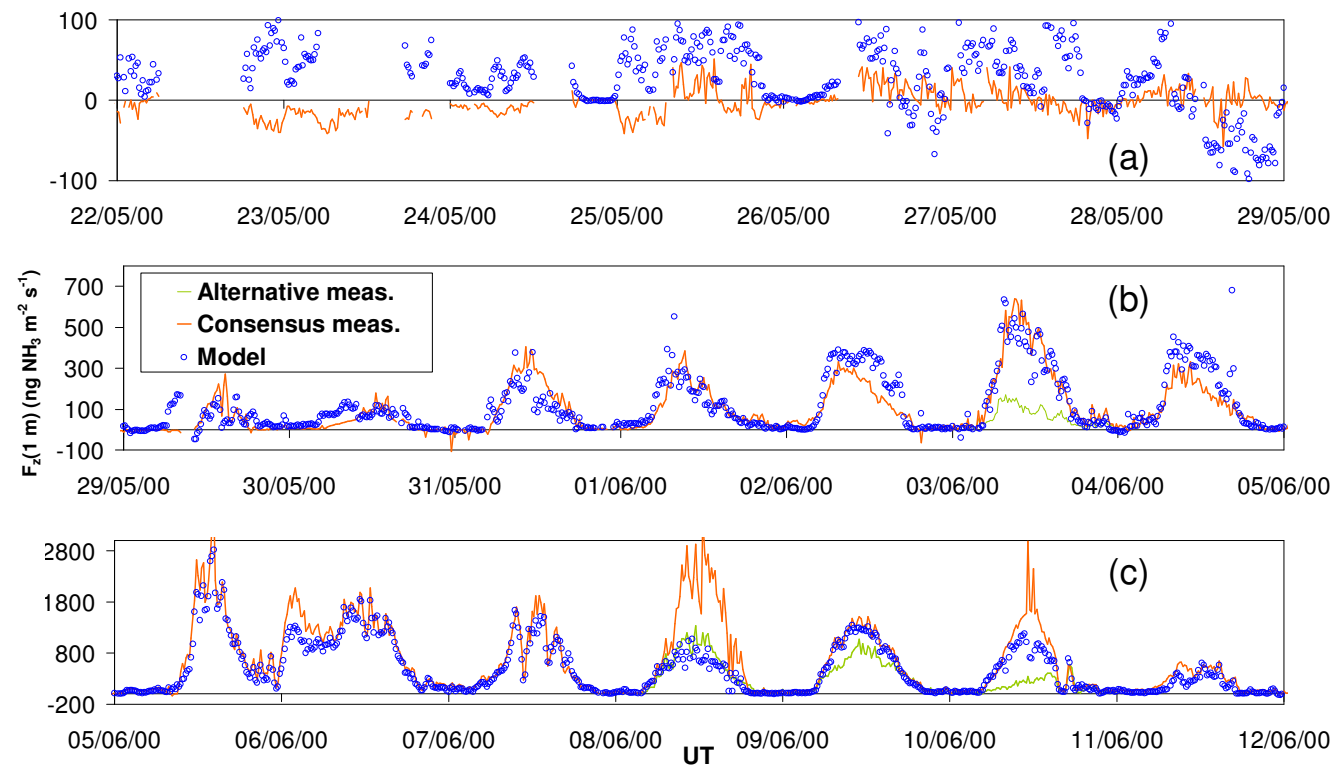

Fig. 11. Ammonia flux at $z=1 \mathrm{~m}$ at Site 1 measured with the gradient technique (orange line: mean gradient estimate of the flux; green line: alternative gradient estimate of the flux) and the FIDES-2D surface dispersion model (blue circles) during (a) the pre-cut period, (b) the pre-fertilisation period, and (c) the post-fertilisation period. The modelled flux has been inferred with the FIDES-2D model using measured $\chi_{1}, \chi_{\text {bgd }}$, the fetch, as well as $u_{*}, d, z_{0}, L$. The mean gradient flux and the alternative gradient estimate are detailed in Milford et al. (2009).

stability, but not much on $u_{*}$. This is also true for the magnitude of the advection error which is not dependent on $u_{*}$ for constant surface sources (and little dependent for constant surface concentration sources) (Table 2). On the contrary, under stable conditions, the advection error at $1 \mathrm{~m}$ height and $300 \mathrm{~m}$ downwind from the source increases by $30 \%$ above its value in neutral conditions, while unstable conditions it diminishes to $62 \%$ of its value at neutrality. This is expected since instability favours atmospheric dilution which dimin- ishes advection below $1 \mathrm{~m}$ height. The effect of stratification is larger for field emission induced advection errors. The roughness length $z_{0}$ also has a great effect on advection error: the smaller the roughness, the larger the advection error (the reasons are similar as for the effect of thermal stratification). As a rule of thumb, for $z_{0}=10 \mathrm{~mm}$ and $1000 \mathrm{~mm}$, the advection error is 2 times larger and 4 times smaller than for $z_{0}=100 \mathrm{~mm}$, respectively. 


\subsection{The FIDES-2D model as an independent method to infer $\mathrm{NH}_{3}$ fluxes}

The FIDES-2D model (Loubet et al., 2001) has been adapted here to account for both the farm $\mathrm{NH}_{3}$ emissions and the $\mathrm{NH}_{3}$ fluxes above the experimental field. This paper focuses on modelled flux divergence due to advection. However, another notable result is that, in the process of estimating the advection errors due to the field, the FIDES-2D model provided an alternative estimate of the surface flux in the experimental field, in a similar way as presented by Sommer et al. (2005). This modelled flux was compared with the gradient and REA estimates (Hensen et al., 2008; Milford et al., 2009; Sutton et al., 2009). The flux $F_{z}\{1 \mathrm{~m}\}$ at Site 1 inferred with FIDES-2D using only $u_{*}, z_{0}, d, L, \chi_{1}, \chi_{\text {bgd }}$ and the fetch, fits closely to the fluxes measured by the gradient method Fig. 11, as reported for the mean gradient estimate of the flux and the alternative gradient estimate (given for some days where there was particular uncertainty between instruments, Milford et al., 2009). The flux estimated by FIDES$2 \mathrm{D}$ represented in Fig. 11 was estimated assuming a constant surface concentration. The flux estimated with a hypothesis of a constant surface flux was $3 \%$ higher $\left(R^{2}=0.9998\right.$, $\mathrm{n}=2126$ ) than with constant surface concentration.

The use of the FIDES-2D model as a method to infer $\mathrm{NH}_{3}$ fluxes is a notable result for at least two reasons. Firstly, the two methods are relatively independent since the gradient method uses the vertical gradient near the ground and the FIDES-2D method uses the concentration difference between two locations $\left(\chi_{1}(1 \mathrm{~m}), \chi_{\text {bgd }}(42 \mathrm{~m})\right)$. Secondly, this suggests that, when the geometry of the source /sink can be identified, only one concentration measurement close to the ground (1 m height) and one concentration measurement in the background are necessary to infer the fluxes, knowing $u_{*}, z_{0}, d$ and $L$. Note that all data need to be measured on a fine temporal scale ( $30 \mathrm{~min}-2 \mathrm{~h})$. The FIDES inference method worked well when the field was itself the main local source of $\mathrm{NH}_{3}$, therefore driving the concentration change above the field, as is shown in Fig. 2. In a situation where the concentration at $1 \mathrm{~m}$ is driven by background sources located further away, such as during the first week of experiment (upper graph of Fig. 11), the method employed here is much more uncertain. It is also likely to be more difficult to achieve good results in situations where the background and the local concentration are close to each other, due to a larger relative uncertainty in the concentration measurements.

Nevertheless, these results demonstrate the interest of such an inference method. The concentration measurement between an emitting field and a background does not require the same precision as needed in a gradient or a REA flux measurement. Moreover, in this study the inference method can be used to discriminate between the flux measurements methods. In the situations where the mean gradient and alternative gradient fluxes do not agree, especially for days 3 June 2000, 8 June 2000 and 10 June 2000, the FIDES-2D estimate thus provides a valuable independent estimate. On 3 June 2000, the FIDES-2D estimate of the flux matched closely to the mean gradient estimate of the flux, whereas on 8 June 2000 it is closer to the alternative gradient estimate of the flux, and on 10 June 2000 it lies in between the two. Hence this comparison can be useful in interpreting the gradient flux measurements, such as for comparison with process basedmodel estimates (Personne et al., 2009; Sutton et al., 2009; Burkhardt et al., 2009).

\section{Conclusions}

The divergences in the vertical $\mathrm{NH}_{3}$ flux at $1 \mathrm{~m}$ height due to advection over intensively managed grassland have been inferred from an inverse modelling approach and from direct measurements of the horizontal concentration gradients. The advection errors over the experimental field have been shown to result from the combination of advection due to farm emissions and due to emissions from the study field itself. A simple method consisting in adding up these advection fluxes in the model resulted in a combined local advection error, which compared well with the inferred advection error.

The advection error due to the farm emissions was positive ("biased toward emission"), and ranged between approximately 0 and $27 \mathrm{ng} \mathrm{NH}_{3} \mathrm{~m}^{-2} \mathrm{~s}^{-1}$, at $610 \mathrm{~m}$ downwind, and was independent of the field fluxes. Relative to the flux at Site 1 after cutting and fertilisation, advection error due to the farm was small, but it represented $52 \%$ on average before the cut for periods when Site 1 was downwind of the farm. The field-induced advection errors were negative ("bias toward deposition") and represented a small fraction of typically $1.5 \%$ of the flux on average but up to $7 \%$ on occasions.

Measurements of $\mathrm{NH}_{3}$ emissions over an agricultural field could hence lead to a systematic underestimation of $\mathrm{NH}_{3}$ emissions to the atmosphere of up to $7 \%$ due to local advection errors. Conversely, advection errors induced from a point source such as a farm, over semi-natural land are not proportional to the flux, but depend on the farm source magnitude. This study shows that the magnitude of advection errors at $1 \mathrm{~m}$ height, resulting from a farm source is likely to be about $10 \mathrm{ng} \mathrm{NH}_{3} \mathrm{~m}^{-2} \mathrm{~s}^{-1}$ as an order of magnitude at $600 \mathrm{~m}$ downwind of an intensive source, but can reach around $100 \mathrm{ng} \mathrm{NH}_{3} \mathrm{~m}^{-2} \mathrm{~s}^{-1}$ at $100 \mathrm{~m}$ downwind from a farm.

This study shows that in a regional budget, emissions from intensively managed fields would be underestimated ("bias toward deposition) and deposition to semi-natural areas would also be underestimated ("bias toward emission") (Loubet et al., 2001; Milford et al., 2001b). It is however not possible from this study to determine if the overall budget of advection errors is balanced in a regional budget.

This study has proven the usefulness of local dispersion modelling to estimate the advection errors in a complex environment. The use of a 2-D model was however shown to have limitations and the use of a 3-D dispersion and exchange 
model would be interesting for further studies of local advection errors.

Acknowledgements. The work presented here was partly funded by the EU GRAMINAE Project (contract ENV4-CT98-0722), the French Ministry of Research and Education, the French Ministry of Agriculture, the UK Department of Environment Food and Rural Affairs (Air and Environmental Quality Programme), the UK Natural Environment Research Council, and the FAL, Braunschweig. Final synthesis of this paper was conducted as part of the NitroEurope Integrated Project.

Edited by: J. K. Schjoerring

\section{References}

Bouwman, A. F., Lee, D. S., Asman, W. A. H., Dentener, F. J., van der Hoek, K. W., and J.G.J., O.: A global high-resolution emission inventory for ammonia, Global Biogeochem. Cy., 11, 561-587, 1997.

Brost, R. A., Delany, A. C., and Huebert, B. J.: Numerical modeling of concentrations and fluxes of hno3, nh3, and nh4no3 near the surface, J. Geophys. Res.-Atmos., 93, 7137-7152, 1988.

Burkhardt, J., Flechard, C. R., Gresens, F., Mattsson, M., Jongejan, P. A. C., Erisman, J. W., Weidinger, T., Meszaros, R., Nemitz, E., and Sutton, M. A.: Modelling the dynamic chemical interactions of atmospheric ammonia with leaf surface wetness in a managed grassland canopy, Biogeosciences, 6, 67-84, 2009, http://www.biogeosciences.net/6/67/2009/.

Dragosits, U., Sutton, M. A., Place, C. J., and Bayley, A. A.: Modelling the spacial distribution of agricultural ammonia emissions in the uk, Environ. Pollut., 102, 195-203, 1998.

Erisman, J. W. and Wyers, P.: Continuous measurements of surface exchange of so 2 and nh3; inplications for their possible interactions process, Atmos. Environ., 27, 1937-1949, 1993.

Famulari, D., Fowler, D., Hargreaves, K., Milford, C., Nemitz, E., Sutton, M. A., and Weston, K.: Measuring eddy covariance fluxes of ammonia using tunable diode laser absorption spectroscopy, Water Air Soil Poll., 4, 151-158, 2004.

Fangmeier, A., Hadwiger-Fangmeier, A., Van der Eerden, L., and Jager, H.-J.: Effects of atmospheric ammonia on vegetation-a review, Environ. Pollut., 86, 43-82, 1994.

Foken, T., Wimmer, F., Mauder, M., Thomas, C., and Liebethal, C.: Some aspects of the energy balance closure problem, Atmos. Chem. Phys., 6, 4395-4402, 2006, http://www.atmos-chem-phys.net/6/4395/2006/.

Fowler, D., and Duyzer, J. H.: Micrometeorological techniques for the measurement of trace gas exchange, in: Exchange of trace gases between terrestrial ecosystems and the atmosphere, edited by: Endreae, M. O. and Schimel, D. S., John Wiley, New York, 189-207, 1989.

Fowler, D., Coyle, M., Flechard, C., Hargreaves, K., Nemitz, E., Storeton-West, R., Sutton, M., and Erisman, J. W.: Advances in micrometeorological methods for the measurement and interpretation of gas and particle nitrogen fluxes, Plant Soil, 228, 117129, 2001.

Garland, J. A.: The dry deposition of sulphur dioxide to land and water surfaces, P. Roy. Soc. Lond. A Mat, 354, 245-268, 1977.
Hensen, A., Nemitz, E., Flynn, M. J., Blatter, A., Jones, S. K., Sørensen, L. L., Hensen, B., Pryor, S., Jensen, B., Otjes, R. P., Cobussen, J., Loubet, B., Erisman, J. W., Gallagher, M. W., Neftel, A., and Sutton, M. A.: Inter-comparison of ammonia fluxes obtained using the relaxed eddy accumulation technique, Biogeosciences Discuss., 5, 3965-4000, 2008,

http://www.biogeosciences-discuss.net/5/3965/2008/.

Hensen, A., Loubet, B., Mosquera, J., van den Bulk, W. C. M., Erisman, J. W., Daemmgen, U., Milford, C., Lopmeier, F. J., Cellier, P., Mikuska, P., and Sutton, M. A.: Estimation of nh3 emissions from a naturally ventilated livestock farm using local-scale atmospheric dispersion modelling, Biogeosciences Discuss., 6, 825862,2009 ,

http://www.biogeosciences-discuss.net/6/825/2009/.

Hertel, O., Skjoth, C. A., Lofstrom, P., Geels, C., Frohn, L. M., Ellermann, T., and Madsen, P. V.: Modelling nitrogen deposition on a local scale - a review of the current state of the art, Environ. Chem., 3, 317-337, doi:10.1071/en06038, 2006.

Huang, C. H.: A theory of dispersion in turbulent shear flow, Atmos. Environ., 13, 453-463, 1979.

Itier, B., Brunet, Y., McAneney, K. J., and Lagouarde, J.P.: Downwind evolution of scalar fluxes and surface resistance under conditions of local advection.Part i: A rappraisal of boundary conditions, Agr. Forest Meteorol., 71, 211-225, 1994.

Kaimal, J. C. and Finnigan, J. J.: Atmospheric boundary layer flows, their structure and measurement., Oxford University Press., New York, 289 pp., 1994.

Keuken, M. P., Schoonebeek, C. A. M., Van Wensveen-Louter, A., and Slanina, J.: Simultaneaous sampling of nh3 hno3, hci, so2, and $\mathrm{h} 2 \mathrm{o} 2$ in ambient air by a wet annular denuder system, Atmos. Environ., 22, 2541-2548, 1988.

Kruit, R. J. W., van Pul, W. A. J., Otjes, R. P., Hofschreuder, P., Jacobs, A. F. G., and Holtslag, A. A. M.: Ammonia fluxes and derived canopy compensation points over non-fertilized agricultural grassland in the netherlands using the new gradient ammonia - high accuracy - monitor (graham), Atmos. Environ., 41, 1275-1287, doi:10.1016/j.atmosenv.2006.09.039, 2007.

Krupa, S. V.: Effects of atmospheric ammonia (nh3) on terrestrial vegetation: A review, Environ. Pollut., 124, 179-221, 2003.

Laville, P., Jambert, C., Cellier, P., and Delmas, R.: Measurements of nitrous oxide fluxes in a fertilised maize crop by micrometeorological and chamber methods, Agr. Forest Meteorol., 96, 19-38, 1999.

Lee, X. H., Yu, Q., Sun, X., Liu, J., Min, Q., Liu, Y., and Zhang, X.: Micrometeorological fluxes under the influence of regional and local advection: A revisit, Agr. Forest Meteorol., 122, 111-124, 2004.

Leuning, R., Freney, J. R., Denmead, O. T., and Simpson, J. R.: A sampler for measuring atmospheric ammonia flux, Atmos. Environ., 19, 1117-1124, 1985.

Loubet, B., Milford, C., Sutton, M. A., and Cellier, P.: Investigation of the interaction between sources and sinks of atmospheric ammonia in an upland landscape using a simplified dispersionexchange model, J. Geophys. Res.-Atmos., 106, 24 183-24 195, 2001.

Loubet, B., Cellier, P., Milford, C., and Sutton, M. A.: A coupled dispersion and exchange model for short-range dry deposition of atmospheric ammonia, Q. J. Roy. Meteorol. Soc., 132, 17331763, 10.1256/qj.05.73, 2006. 
McInnes, K. J., Kissel, D. E., and Kanemasu, E. T.: Estimating ammonia flux: A comparison between the integrated horizontal flux method and theoretical solutions of the diffusion profile, Agron. J., 77, 884-889, 1985.

Milford, C., Hargreaves, K. J., Sutton, M. A., Loubet, B., and Cellier, P.: Fluxes of nh3 and co2 over upland moorland in the vicinity of agricultural land, J. Geophys. Res.-Atmos., 106, 24 16924 181, 2001a.

Milford, C., Theobald, M. R., Nemitz, E., and Sutton, M. A.: Dynamics of ammonia exchange in response to cutting and fertilising in an intensively-managed grassland, Water Air Soil Poll., 1, 167-176, 2001b.

Milford, C., Theobald, M. R., Nemitz, E., Hargreaves, K. J., Horvath, L., Raso, J., Dämmgen, U., Neftel, A., Jones, S. K., Hensen, A., Loubet, B., Cellier, P., and Sutton, M. A.: Ammonia fluxes in relation to cutting and fertilization of an intensively managed grassland derived from an inter-comparison of gradient measurements, Biogeosciences, 6, 819-834, 2009, http://www.biogeosciences.net/6/819/2009/.

Nemitz, E., Sutton, M. A., Fowler, D., Choularton, T. W., and Gallagher, M. W.: Modelling the size-dependent concentration and flux profiles of nh4no3 aerosol modified by gas-to-particle conversion of nh3 and hno3, Proceeding of EUROTRAC Symposium' 96, 205-209, 1996.

Nemitz, E., Sutton, M. A., Wyers, G. P., Otjes, R. P., Schjørring, J. K., Gallagher, M. W., Parrington, J., Fowler, D., and Choularton, T. W.: Surface/atmosphere exchange and chemical interaction of gases and aerosols over oilseed rape, Agr. Forest Meteorol., 105, 427-445, 2000.

Nemitz, E. and Sutton, M. A.: Gas-particle interactions above a dutch heathland: Iii. Modelling the influence of the nh3-hno3nh4no3 equilibrium on size-segregated particle fluxes, Atmos. Chem. Phys., 4, 1025-1045, 2004,

http://www.atmos-chem-phys.net/4/1025/2004/.

Nemitz, E., Sutton, M. A., Wyers, G. P., Otjes, R. P., Mennen, M. G., van Putten, E. M., and Gallagher, M. W.: Gas-particle interactions above a dutch heathland: Ii. Concentrations and surface exchange fluxes of atmospheric particles, Atmos. Chem. Phys., 4, 1007-1024, 2004, http://www.atmos-chem-phys.net/4/1007/2004/.

Nemitz, E., Dorsey, J. R., Flynn, M. J., Gallagher, M. W., Hensen, A., Erisman, J.-W., Owen, S. M., Dämmgen, U., and Sutton, M. A.: Aerosol fluxes and particle growth above managed grassland, Biogeosciences Discuss., 6, 341-389, 2009a, http://www.biogeosciences-discuss.net/6/341/2009/.

Nemitz, E., Hargreaves, K. J., Neftel, A., Loubet, B., Cellier, P., Dorsey, J. R., Flynn, M., Hensen, A., Weidinger, T., Meszaros, R., Horvath, L., Dämmgen, U., Frühauf, C., Löpmeier, F. J., Gallagher, M. W., and Sutton, M. A.: Intercomparison and assessment of turbulent and physiological exchange parameters of grassland, Biogeosciences Discuss., 6, 241-290, 2009b, http://www.biogeosciences-discuss.net/6/241/2009/.

Personne, E., Loubet, B., Herrmann, A., Mattson, M., Schjoerring, J. K., Nemitz, E., Sutton, M. A., and Cellier, P.: Surfatm-nh3: A model combining the surface energy balance and bi-directional exchanges of ammonia applied at the field scale, Biogeosciences Discuss., 6, 71-114, 2009,

http://www.biogeosciences-discuss.net/6/71/2009/.
Philip, J. R.: The theory of local advection, J. Meteorol., 16, 535547, 1959.

Raupach, M. R.: A pratical lagrangian method for relating scalar concentrations to source distribution in vegetation canopies, Q. J. Roy. Meteor. Soc., 115, 609-632, 1989.

Sommer, S. G., Genermont, S., Cellier, P., Hutchings, N. J., Olesen, J. E., and Morvan, T.: Processes controlling ammonia emission from livestock slurry in the field, Eur. J. Agron., 19, 465-486, 2003.

Sommer, S. G., McGinn, S. M., and Flesch, T. K.: Simple use of the backwards lagrangian stochastic dispersion technique for measuring ammonia emission from small field-plots, Eur. J. Agron., 23, 1-7, 2005.

Sutton, M. A., Fowler, D., and Moncrieff, J. B.: The exchange of atmospheric ammonia with vegetated surfaces.I: Unfertilized vegetation, Q. J. Roy. Meteor. Soc., 119, 1023-1045, 1993.

Sutton, M. A., Schjorring, J. K., and Wyers, G. P.: Plant-atmosphere exchange of ammonia, Philos. T. R. Soc. Lond., 351, 261-278, 1995.

Sutton, M. A., Milford, C., Dragosits, U., Place, C. J., Singles, R. J., Smith, R. I., Pitcairn, C. E. R., Fowler, D., Hill, J., ApSimon, H. M., Ross, C., Hill, R., Jarvis, S. C., Pain, B. F., Phillips, V. C., Harrison, R., Moss, D., Webb, J., Espenhahn, S. E., Lee, D. S., Hornung, M., Ullyett, J., Bull, K. R., Emmett, B. A., Lowe, J., and Wyers, G. P.: Dispersion, deposition and impacts of atmospheric ammonia: Quantifying local budgets and spatial variability, Environ. Pollut., 102, 349-361, 1998.

Sutton, M. A., Milford, C., Nemitz, E., Theobald, M. R., Hill, P. W., Fowler, D., Schjørring, J. K., Mattsson, M. E., Nielsen, K. H., Husted, S., Erisman, J. W., Otjes, R., Hensen, A., Mosquera, J., Cellier, P., Loubet, B., David, M., Genermont, S., Neftel, A., Blatter, A., Herrmann, B., Jones, S. K., Horvath, L., Fuhrer, E. C., Mantzanas, K., and Koukoura, Z.: Biosphere-atmosphere interactions of ammonia with grasslands: Experimental strategy and results from a new european initiative, Plant Soil, 228, 131$145,2001$.

Sutton, M. A., Erisman, J. W., Dentener, F., and Moller, D.: Ammonia in the environment: From ancient times to the present, Environ. Pollut., 156, 583-604, 10.1016/j.envpol.2008.03.013, 2008.

Sutton, M. A., Nemitz, E., Theobald, M. R., Milford, C., Dorsey, J. R., Gallagher, M. W., Hensen, A., Jongejan, P. A. C., Erisman, J. W., Mattsson, M., Schjoerring, J. K., Cellier, P., Loubet, B., Roche, R., Neftel, A., Hermann, B., Jones, S. K., Lehman, B. E., Horvath, L., Weidinger, T., Rajkai, K., Burkhardt, J., Lopmeier, F. J., and Daemmgen, U.: Dynamics of ammonia exchange with cut grassland: Strategy and implementation of the graminae integrated experiment, Biogeosciences, 6, 309-331, 2009, http://www.biogeosciences.net/6/309/2009/.

Thomson, D. J.: Criteria for the selection of stochastic models of particle trajectories in turbulent flows, J. Fluid Mech., 180, 529556, 1987.

van der Eerden, L. J. M., de Visser, P. H. B., and van Dijk, C. J.: Risk of damage to crops in the direct neighbourhood of ammonia sources, Environ. Pollut., 102, 49-53, 1998.

Walker, J., Spence, P., Kimbrough, S., and Robarge, W.: Inferential model estimates of ammonia dry deposition in the vicinity of a swine production facility, 1st Workshop on Agricultural Air Quality - State of the Science, Potomac, MD, 
ISI:000256561100017, 3407-3418, 2006a.

Walker, J. T., Robarge, W. P., Wu, Y., and Meyers, T. P.: Measurement of bi-directional ammonia fluxes over soybean using the modified bowen-ratio technique, Agr. Forest Meteorol., 138, 54-68, doi:10.1016/j.agrformet.2006.03.011, 2006 b.

Whitehead, J. D., Twigg, M., Famulari, D., Nemitz, E., Sutton, M. A., Gallagher, M. W., and Fowler, D.: Evaluation of laser absorption spectroscopic techniques for eddy covariance flux measurements of ammonia, Environ. Sci. Technol., 42, 2041-2046, 2008.
Wilson, J. D.: An approximate analytical solution to the diffusion equation for short-range dispersion from a continuous groundlevel source, Bound.-Lay. Meteorol., 23, 85-103, 1982.

Wyers, G. P., Otjes, R. P., and Slanina, J.: A continuous-flow denuder for the measurement of ambient concentrations and surface-exchange fluxes of ammonia, Atmos. Environ., 27A, 2085-2090, 1993.

Yeh, G. T., and Huang, C. H.: Three-dimensional air pollutant modeling in the lower atmosphere, Bound.-Lay. Meteorol., 9, 381390, 1975. 